\title{
Efficacy of Definite Concurrent Chemoradiotherapy for Patients with Limited-Disease Small-Cell Lung Cancer: A Retrospective, Nationwide, Population-Based Cohort Study
}

\section{Yoon Ho Ko ( $\square$ koyoonho@catholic.ac.kr)}

Catholic University of Korea School of Medicine

\section{Seoree Kim}

Catholic University of Korea School of Medicine Department of Internal Medicine

\section{Ji Hyung Hong}

Catholic University of Korea School of Medicine Department of Internal Medicine

\section{Soo-Yoon Sung}

department of radiation oncology, college of medicine, the catholic university of korea

\section{Yeo Hyung Kim}

department of rehabilitation medicine, college of medicine, the catholic university of korea

\section{Sang Hoon Chun}

Catholic University of Korea School of Medicine Department of Internal Medicine

Hyun Woo Lee

department of hematology-oncology, Ajou university of medicine, suwon

Jung Soo Lee

department of rehabilitation medicine, college of medicine, the catholic university of korea

\section{Research article}

Keywords: Cohort study, Chemoradiotherapy, Efficacy, Small-cell lung carcinoma

Posted Date: July 16th, 2020

DOI: https://doi.org/10.21203/rs.3.rs-42549/v1

License: (ㅇ) (1) This work is licensed under a Creative Commons Attribution 4.0 International License. Read Full License

Version of Record: A version of this preprint was published at BMC Cancer on March 31st, 2021. See the published version at https://doi.org/10.1186/s12885-021-08082-2. 


\section{Abstract}

Background: Small-cell lung cancer (SCLC) is a highly proliferative, rapidly growing tumor with a poor prognosis, even in cases of limited disease (LD). Timely and accurate high-intensity therapy is necessary. For concurrent chemoradiotherapy (CCRT), etoposide/platinum (EP)-based regimens are recommended, although irinotecan/platinum (IP)-based regimens are also effective with radiotherapy. This large-scale, retrospective, nationwide cohort study aimed to analyze the efficacy of CCRT in patients with LD-SCLC.

Methods: Population data registered between January 2008 and December 2018 were extracted from the Health Insurance Review and Assessment Service of Korea database. Survival outcomes of 4,446 LD-SCLC patients who received CCRT were analyzed.

Results: Patients who received EP-CCRT $(n=4,187)$ showed better progression-free survival (PFS: 11.2 months) and overall survival (OS: 22.2 months) than did those who received IP-CCRT ( $\mathrm{n}=259$; PFS: 9.6 months, $P=$ 0.0477; OS: 16.4 months, $P<0.0001)$. When CCRT failed, dual-agent chemotherapy ( $n=925 ;$ OS: 9.1 months) provided a better survival benefit than did single-agent chemotherapy ( $n=815 ; 0 S: 7.5$ months). IP-based chemotherapy resulted in better OS (9.6 months) than did EP-based chemotherapy ( 7.1 months, $P=0.0170)$ in platinum-resistant relapsed patients; the opposite was observed for platinum-sensitive relapsed patients (OS: EP, 17.2 months; IP, 6.6 months; $P<0.0001)$. Cox proportional hazards regression analysis demonstrated that age, EP-CCRT, and hypercholesterolemia retained significant associations with OS after adjustment for all variables.

Conclusion: In the Korean population, the effects of EP-CCRT on OS and PFS are significantly more favorable than those of IP-CCRT.

\section{Background}

Small-cell lung cancer (SCLC) is an aggressive lung cancer subtype that accounts for only $12-15 \%$ of all lung cancer diagnoses [1, 2]. At diagnosis, approximately a third of patients have limited-disease (LD) SCLC. The limited-stage disease is confined to the ipsilateral hemithorax or mediastinal or supraclavicular lymph nodes, which can be safely encompassed within a radiation field; whereas, metastatic tumors are categorized under extensive-disease (ED) SCLC [1]. For LD-SCLC, the median survival and 2-year survival rate have been assessed to be 15-20 months and 20-40\%, respectively. Importantly, the proportion of patients who survive for 5 years is reportedly only $14-26 \%$ [2]. Although LD-SCLC is a potentially curable disease, it exhibits a high histological proliferation rate and clinically varied manifestations such as paraneoplastic syndromes; therefore, any wastage of time can result in a change in the treatment modality and worsen the prognosis [2,3].

Almost two decades ago, the addition of twice-daily radiotherapy to combination chemotherapeutic agents was the cornerstone of LD-SCLC treatment $[4,5]$, with the strategies significantly improving the survival of patients with LD-SCLC. In the era of immunotherapy, there has been a paradigm shift in the treatment of SCLC [6, 7]; however, concurrent chemoradiotherapy (CCRT) remains the current standard treatment worldwide [2, 3]. In previous studies, the overall response rate after CCRT reached $\geq 80 \%$, with a complete remission rate of up to $45 \%[8,9]$. A large proportion of patients died from recurrence and distant metastasis. These findings result in constantly unmet needs for the development of chemotherapeutic agents and combinations that exhibit 
greater antitumor effects and superior radiosensitization. CCRT based on an etoposide/platinum (EP)-based regimen has been the standard protocol since the early 1990s. In addition, an irinotecan/platinum (IP)-based regimen with radiation treatment has been reported to be effective and tolerable for patients with untreated LDSCLC $[10,11]$. Although several studies have verified the effectiveness of the two regimens in cases of LDSCLC with similar schemes [8, 10-15], to our knowledge, no large-scale study has included LD-SCLC patients from an East Asian population. Therefore, we conducted a nationwide study to analyze the efficacy of definite CCRT in a large population of Korean patients with LD-SCLC using data from the Health Insurance Review and Assessment Service (HIRA) database. Korean health insurance covers the entire population of Korea, and HIRA provides information on healthcare services provided to the Korean population. Thus, by using the HIRA database, we could approach the entire Korean population.

\section{Methods}

\section{Ethical statement}

This study was approved by the Institutional Review Board of the Uijeongbu St. Mary Hospital, College of Medicine, Catholic University of Korea [UC18ZESI0145], and it conforms to the provisions of the Helsinki Declaration as revised in 2013 (available at: https://www.wma.net/policies-post/wma-declaration-of-helsinkiethical-principles-for-medical-research-involving-human-subjects/). The need for informed consent was waived because of the retrospective nature of the study.

\section{Study design and population}

To verify the reliability of the operational criteria for SCLC staging, we used single-institution data from 357 SCLC patients with known disease status. Using these operational criteria, patients with LD-SCLC were predicted with a sensitivity of $64.6 \%$, specificity of $100 \%$, and accuracy of $88.5 \%$ (Supplementary Table 2 ). This operational definition facilitates identification of most cases of LD-SCLC and completely rules out ED. Thus, these definitions can be used to specifically select patients with LD-SCLC. The median survival time of LDSCLC patients was 21.8 months (95\% confidence interval [CI], 20.86-22.96), defined per our operational criteria, while that of ED-SCLC patients was 9.6 months ( $95 \% \mathrm{Cl}, 9.43-9.83$; Supplementary Fig. 1). The corresponding 5-year survival rates were $24.73 \pm 0.75 \%$ and $8.13 \pm 0.30 \%$, respectively. These findings were comparable with those for patients with LD-SCLC and ED-SCLC in recent studies $[2,16,17]$. Thus, our operational criteria were considered acceptable.

\section{Definition of survival outcomes}

The primary objective was to evaluate the survival outcomes of LD-SCLC patients after CCRT. Progression-free survival (PFS) was defined as the time from the date of first-line chemotherapy to the time of subsequent chemotherapy or death from any cause, whichever was earlier. Overall survival (OS) was calculated as the time from the date of diagnosis to the date of death or the last follow-up visit. The date of diagnosis was defined as the date of initiation of the first chemotherapy, surgery, or radiotherapy after the first-ever application of the C34 diagnostic code. For the patients who received second-line chemotherapy, OS was calculated from the start date of the second-line chemotherapy regimen to the date of death or the last follow-up visit. 


\section{Statistical analysis}

Concerning baseline characteristics, continuous variables were processed as means ( \pm standard errors) or medians (range), while categorical variables were expressed as frequencies (\%). A $t$-test was used for comparisons of continuous variables, and Pearson's chi-square test or the two-sample proportion z-test was used for comparisons of categorical variables. Cox proportional hazards regression analysis was performed to identify the risk factors for overall mortality. Survival curves were generated using the Kaplan-Meier method and compared using the log-rank test. The SAS Enterprise Guide version 6.1 (SAS Inc., Cary, NC, USA), Python 3.74 (Python Software Foundation), Visual Basic for Applications 7.0 (Microsoft Inc., Redmond, WA, USA), and Excel 2010 (Microsoft Inc.) were used for all data mining and statistical analyses.

\section{Results}

\section{Baseline characteristics}

A total of 4,446 patients were included in our study. The baseline characteristics of the patients are summarized in Table 1. The mean age was 64 years, and $85.4 \%$ of patients were male. In total, 2,187 (49.2\%) patients were young ( $<65$ years) while 2,259 (50.8\%) were elderly ( $\geq 65$ years). Concerning CCRT, 4,187 (94.2\%) and 259 (5.8\%) received EP-CCRT and IP-CCRT, respectively. Second-line treatment was received by 1,740 patients because of the failure of definite CCRT or progression during treatment; 925 (53.2\%) received combination chemotherapy, and 815 (46.8\%) received single-agent chemotherapy.

\section{Clinical outcomes of definite CCRT and second-line treatment}

Median PFS was significantly longer with EP-CCRT (11.2 months, 95\% Cl: 10.90-11.67) than with IP-CCRT (9.6 months, 95\% Cl: 8.50-10.67; $P=0.0477$; Fig. 2A). OS was also significantly longer with EP-CCRT (22.2 months, $95 \%$ Cl: $21.23-23.33)$ than with IP-CCRT (16.4 months, $95 \%$ Cl: $14.47-18.33 ; P<0.0001$; Fig. 2B). Among patients who received second-line chemotherapy, those who received combination chemotherapy showed a better survival benefit ( 9.1 months, $95 \% \mathrm{Cl}: 8.40-10.10)$ than did those who received monotherapy $(7.5$ months, 95\% Cl: 6.93-8.13; $P<0.0001$; Fig. 3A). Concerning the combination chemotherapy regimens, the EP combination resulted in significantly better OS (11.2 months, $95 \% \mathrm{Cl}: 8.87-13.27)$ than did the IP combination (8.9 months, 95\% Cl: 8.23-9.67; $P=0.0128 ;$ Fig. 3B). However, there were no significant differences in OS among single-agent regimens used for second-line treatment $(P=0.3712$; Supplementary Fig. 2).

\section{Clinical outcomes of second-line treatment according to PFS of $<6$ months or $>6$ months after CCRT}

Patients who received second-line treatment were classified into platinum-resistant and platinum-sensitive relapsed groups according to PFS of $<6$ months and $>6$ months after CCRT, respectively. In the platinumresistant relapsed group, second-line IP-based chemotherapy resulted in significantly better OS (9.6 months, $95 \% \mathrm{Cl}: 8.67-10.33)$ than did second-line EP-based chemotherapy (7.1 months, 95\% Cl: 5.10-10.40; $P=$ 0.0170; Supplementary Fig. 3A). Conversely, second-line EP-based chemotherapy (OS: 17.2 months, $95 \% \mathrm{Cl}$ : 13.03-25.63) was superior to second-line IP-based chemotherapy (OS: 6.6 months, 95\% Cl: 5.43-7.77; $P$ $<0.0001$; Supplementary Fig. 3B) in the platinum-sensitive relapsed group. 


\section{Factors associated with survival outcomes in patients with LD-SCLC}

The results of univariate and multivariate analyses of risk factors for poor survival in patients with LD-SCLC are listed in Table 2. Univariate analysis demonstrated that older age, the male sex, the presence of hypertension, the absence of hypercholesterolemia, and the use of IP-CCRT as definite treatment were significantly associated with shorter OS. In the multivariate analysis, variables that were significantly associated with poor survival included older age (adjusted hazard ratio [HR]: 1.64, 95\% Cl: 1.45-1.85; $P$ $<0.0001$ ), the absence of hypercholesterolemia (adjusted HR: $1.23,95 \% \mathrm{Cl}: 1.10-1.39 ; P<0.0001$ ), and the use of IP-CCRT as definite treatment (adjusted HR: 19.47, 95\% Cl: 6.13-61.77; $P<0.0001$ ).

\section{Discussion}

In the present population-based study, we investigated the efficacy of definite CCRT using real-world data for patients with LD-SCLC. The results revealed that the survival outcomes patients who received EP-CCRT were better than those patients who received IP-CCRT. As second-line treatment in cases of CCRT failure or progression during treatment, the EP regimen resulted in better OS than did the IP regimen; however, the IP regimen was more effective in patients with PFS of $<6$ months after CCRT, i.e., platinum-resistant relapsed patients. This study provides evidence that the EP combination should be the gold standard for CCRT in Korean patients with LD-SCLC. To the best of our knowledge, this analysis included the largest study population till date.

Previous studies have provided sufficient evidence for the advantages of the EP regimen over other regimens for CCRT $[2,5,9]$. EP-based chemotherapy, combined with concurrent thoracic radiotherapy, has been considered the standard of care for patients with LD-SCLC, with lesser toxic effects on intrathoracic organs and the ability for radiosensitization [9]. Previous randomized trials have suggested that concurrent thoracic radiotherapy and EP-based chemotherapy is better than older regimens such as doxorubicin-based or cyclophosphamide-based ones $[9,18]$. Despite a better response to chemotherapy alone, doxorubicin-based or cyclophosphamide-based CCRT showed a median OS period of just 15 months in patients with LD-SCLC. These unsatisfactory results may be partially attributed to significant toxic effects such as more myelosuppression, weight loss, esophagitis, and pulmonary dysfunction $[9,19,20]$.

In a recent randomized trial including a Korean population, IP-based chemotherapy had significantly favorable effects on survival outcomes when compared to EP-based chemotherapy for previously untreated ED-SCLC [17]. Similar findings were reported in a meta-analysis of six trials involving 1,476 patients [21]. In addition to having cytotoxic effects on SCLC, irinotecan is known to be a potent radiosensitizing agent [22], and the IP combination has been adopted as the chemotherapy regimen in CCRT for LD-SCLC. Although it has been shown that IP-based chemoradiotherapy is effective and tolerable in Asian and Western populations, there has been no direct comparison between EP-CCRT and IP-CCRT. Table 3 summarizes the results of previous studies on EP-CCRT and IP-CCRT for LD-SCLC. In a nutshell, the efficacy of IP-CCRT was comparable to that of EPCCRT in patients with untreated LD-SCLC. The results of phase II trials showed that median survival with IPbased CCRT was 12.4-44.5 months, which was comparable to the survival time with EP-CCRT; however, there were considerable discrepancies in results among different studies $[4,8,10-15,23]$. In a phase II study in 
Japan, IP-based chemotherapy with concurrent split-course radiotherapy showed a remarkable survival benefit, with a median time to progression of 14.5 months and a median OS duration of 44.5 months [11]. However, in a phase II trial in Korean patients with LD-SCLC, median OS was 20.0 months, with 1-year and 2-year OS rates of $85 \%$ and $35 \%$, respectively [23]. Similarly, in a western phase II trial, the overall radiographic response rate was $67 \%$, median OS was 19 months, and the 1-year and 2-year OS rates were $60 \%$ and $44 \%$, respectively [10].

However, these substantial differences in efficacy among studies on IP-based CCRT may be explained by differences in the timing of radiotherapy and its optimal dose, fractionation of thoracic radiotherapy, and consolidation chemotherapy. Pneumonitis and neutropenia were the main toxicities caused by IP-CCRT. Of note, pneumonitis is an important problem associated with IP-based chemoradiotherapy [20]. A study by Ohe et al. showed that pulmonary fibrosis identified on plain chest X-rays was a very strong risk factor for thoracic radiotherapy-related death [19], and that CCRT-related deaths occurred in 25 of 926 (2.7\%) patients, including seven $(28 \%)$ with radiation pneumonitis [19]. In the real-world setting, the rate of poor prognostic factors, the proportion of elderly patients, or the presence of comorbidities may be higher. Furthermore, patient compliance may be poorer, and routine medical practice may differ from protocol-specific patient care provided in clinical trials [24]. In the present study, patients who received EP-CCRT showed significantly better PFS and OS than did those who received IP-CCRT. Thus, treatment-related toxicities, including pulmonary toxicities, may have an unfavorable impact on the patients' clinical outcomes. Taken together, the EP regimen should be strongly considered as a concurrent chemotherapeutic regimen in definite CCRT for LD-SCLC.

Recently, Horn et al. demonstrated better PFS and OS when atezolizumab was added to chemotherapy for EDSCLC than when only chemotherapy was used (OS, 12.3 vs. 10.3 months; PFS, 5.2 vs. 4.3 months) [6]. Of note, xenograft models have proved the synergistic effects of radiotherapy with immune checkpoint inhibitors [25], which are expected to have promising clinical efficacy through low toxicity and abscopal effects in several ongoing studies [NCT03811002, NCT02402920] regarding LD-SCLC.

Concerning the strategy of using cytotoxic chemotherapy as a second-line treatment for LD-SCLC, there is no consensus on the most effective regimen. In the present study, patients who received combination chemotherapy as a second-line treatment showed significantly better OS than did those who received single agents as second-line treatment; this finding is consistent with that of a previous study [26]. Multi-agent chemotherapy has historically demonstrated response rates higher than those shown by single-agent chemotherapy in cases of relapsed SCLC. However, these better rates have often been achieved with an increase in toxicities. A recent Japanese phase III trial demonstrated the superiority of the cisplatin, irinotecan, and etoposide combination over topotecan alone as a second-line regimen for platinum-sensitive relapsed SCLC (OS: 18.2 vs. 12.5 months, HR: 0.67, 95\% Cl: 0.51-0.88; $P=0.0079$ ) [26]. However, it has been emphasized that this combination should be administered only in select patients, such as those with platinumsensitive relapsed SCLC, because of associated toxicities.

Clinically, the differentiation of platinum-sensitive and platinum-resistant SCLC patients is essential. Although there are some reports about the association between the platinum sensitivity status and clinical outcomes in patients with relapsed SCLC, the role of the platinum sensitivity status remains controversial [27]. In a previous study, cross-administration of chemotherapy was effective in the platinum-resistant relapsed group [27]. In the 
present analysis, we could confirm that IP-based chemotherapy resulted in better OS than did EP-based chemotherapy in platinum-resistant relapsed patients, defined by PFS of $<6$ months after CCRT.

Poor prognostic factors for patients with LD-SCLC included older age, the male sex, the absence of hypercholesterolemia, and the use of IP-CCRT as definite treatment. There are many conflicting reports about the prognostic role of lipidemia in cancer patients. Some studies have shown that malignant aerobic glycolysis, or the Warburg effect, leads to efficient biomass synthesis, including lipid synthesis, which is required for malignant cell proliferation [28]. In contrast, adipose tissue modulates the storage of extrinsic potential carcinogens such as benzo(a)pyrene, which induces DNA adduct formation and prevents the accumulation of carcinogen-DNA adducts in target organs, resulting in reduced cancer risk [29].

Hypocholesterolemia is often observed in patients with advanced-stage cancer, probably because of increased demand for cholesterol by neoplastic cells, which results in increased low-density lipoprotein cholesterol removal. This dynamicity is involved in the prognosis of SCLC, regulating the metabolism of lipids as dynamic organelles [30].

This study has several limitations that must be considered when interpreting the results. First, several potential information biases might exist. The HIRA data were retrospectively analyzed, and there was no information regarding the radiation dose, chemotherapy dose intensity, frequency of adverse treatment-related reactions, and causes of death. Second, identification of LD-SCLC or ED-SCLC patients as per the operational definition may be associated with bias. However, to overcome such bias, we used a strict multistep approach, and the Kaplan-Meier curves for LD-SCLC and ED-SCLC showed results similar to those in recent studies. Moreover, the clinical implications were validated through single-institute pooled analysis.

The results of this study suggest that the effects of EP-CCRT on OS and PFS are significantly more favorable than those of IP-CCRT in Korean patients with LD-SCLC. In cases where CCRT fails, combination chemotherapy provides a better survival benefit than does single-agent chemotherapy. Moreover, in CCRT failure cases with PFS of $<6$ months (platinum-resistant relapsed patients), IP-based chemotherapy has significantly better effects on OS and PFS than does EP-based chemotherapy.

\section{Abbreviations}

SCLC

Small-cell lung cancer; LD:limited disease; CCRT:concurrent chemoradiotherapy:EP:etoposide/platinum; IP:irinotecan/platinum; PFS:progression-free survival; OS:overall survival; ED:extensive-disease; HIRA:Health Insurance Review and Assessment Service; ICD:International Classification of Diseases; NHIS:National Health Insurance Service; Cl:confidence interval; HR:hazard ratio;

\section{Declarations}

\section{Acknowledgements}

None.

\section{Author's contributions}


YHK and JSL generated conception of the work; JSL, YHK, JHH, YHK, HWL, SRK, SYS got acquisition, analysis, and interpretation of the data; YHK, JSL, SRK have drafted the work; and JSL, SRK, YHK substantially revised it. All authors reviewed the manuscript.

\section{Funding}

None.

\section{Availability of data and materials}

All data analysed during this study are included in this published article.

\section{Ethics approval and consent to participate}

Not applicable.

\section{Consent for publication}

Not applicable.

\section{Competing interests}

The authors have no conflicts of interest to declare.

\section{References}

1. Nicholson AG, Chansky K, Crowley J, Beyruti R, Kubota K, Turrisi A, et al. The International Association for the Study of Lung Cancer Lung Cancer staging project: proposals for the revision of the clinical and pathologic staging of small cell lung cancer in the forthcoming eighth edition of the TNM classification for lung cancer. J Thorac Oncol. 2016;11(3):300-11.

2. van Meerbeeck JP, Fennell DA, De Ruysscher DK. Small-cell lung cancer. Lancet. 2011;378(9804):1741-55.

3. Glatzer M, Rittmeyer A, Muller J, Opitz I, Papachristofilou A, Psallidas I, et al. Treatment of limited disease small cell lung cancer: the multidisciplinary team. Eur Respir J. 2017;50(2):1700422.

4. Faivre-Finn C, Snee M, Ashcroft L, Appel W, Barlesi F, Bhatnagar A, et al. Concurrent once-daily versus twice-daily chemoradiotherapy in patients with limited-stage small-cell lung cancer (CONVERT): an openlabel, phase 3, randomised, superiority trial. Lancet Oncol. 2017;18(8):1116-25.

5. Pignon JP, Arriagada R, Ihde DC, Johnson DH, Perry MC, Souhami RL, et al. A meta-analysis of thoracic radiotherapy for small-cell lung cancer. N Engl J Med. 1992;327(23):1618-24.

6. Horn L, Mansfield AS, Szczesna A, Havel L, Krzakowski M, Hochmair MJ, et al. First-line atezolizumab plus chemotherapy in extensive-stage small-cell lung cancer. N Engl J Med. 2018;379(23):2220-9.

7. Li Q, Yuan D, Ma C, Liu Y, Ma L, Lv T, et al. A new hope: the immunotherapy in small cell lung cancer. Neoplasma. 2016;63(3):342-50.

8. Sohn JH, Moon YW, Lee CG, Kim GE, Chung KY, Chang J, et al. Phase II trial of irinotecan and cisplatin with early concurrent radiotherapy in limited-disease small-cell lung cancer. Cancer. 2007;109(9):1845-950. 
9. Turrisi AT 3rd, Kim K, Blum R, Sause WT, Livingston RB, Komaki R, et al. Twice-daily compared with oncedaily thoracic radiotherapy in limited small-cell lung cancer treated concurrently with cisplatin and etoposide. N Engl J Med. 1999;340(4):265-71.

10. Naidu SS, Walker PR, Parent T, Picton ME. Limited-stage small cell lung cancer treated with cisplatin/irinotecan and concurrent thoracic radiation therapy. J Clin Oncol. 2014;32(15_suppl):7598.

11. Fukuda M, Nakamura Y, Kinoshita A, Soejima Y, Yamaguchi H, Ikeda T, et al. Phase II study of irinotecan and cisplatin with concurrent split-course radiotherapy in limited-disease small cell lung cancer. Cancer Chemother Pharmacol. 2012;70(5):645-51.

12. Kubota K, Hida T, Ishikura S, Mizusawa J, Nishio M, Kawahara M, et al. Etoposide and cisplatin versus irinotecan and cisplatin in patients with limited-stage small-cell lung cancer treated with etoposide and cisplatin plus concurrent accelerated hyperfractionated thoracic radiotherapy (JCOG0202): a randomised phase 3 study. Lancet Oncol. 2014;15(1):106-13.

13. Hong J, Park YM, Lee SH, Lee KC, Park SH, Park J, et al. Irinotecan and cisplatin combination chemotherapy plus concurrent thoracic irradiation for patients with limited disease small cell lung cancer. J Lung Cancer. 2011;10(1):49-55.

14. Saito H, Takada Y, Ichinose Y, Eguchi K, Kudoh S, Matsui K, et al. Phase Il study of etoposide and cisplatin with concurrent twice-daily thoracic radiotherapy followed by irinotecan and cisplatin in patients with limited-disease small-cell lung cancer: West Japan Thoracic Oncology Group 9902. J Clin Oncol. 2006;24(33):5247-52.

15. Han JY, Cho KH, Lee DH, Kim HY, Kim EA, Lee SY, et al. Phase Il study of irinotecan plus cisplatin induction followed by concurrent twice-daily thoracic irradiation with etoposide plus cisplatin chemotherapy for limited-disease small-cell lung cancer. J Clin Oncol. 2005;23(15):3488-94.

16. Shin A, Oh CM, Kim BW, Woo H, Won YJ, Lee JS. Lung cancer epidemiology in Korea. Cancer Res Treat. 2017;49(3):616-26.

17. Kim DW, Kim HG, Kim JH, Park K, Kim HK, Jang JS, et al. Randomized phase III trial of irinotecan plus cisplatin versus etoposide plus cisplatin in chemotherapy-naive Korean patients with extensive-disease small cell lung cancer. Cancer Res Treat. 2019;51(1):119-27.

18. Pujol JL, Carestia L, Daurès JP. Is there a case for cisplatin in the treatment of small-cell lung cancer? A meta-analysis of randomized trials of a cisplatin-containing regimen versus a regimen without this alkylating agent. Br J Cancer. 2000;83(1):8-15.

19. Ohe Y, Yamamoto S, Suzuki K, Hojo F, Kakinuma R, Matsumoto T, et al. Risk factors of treatment-related death in chemotherapy and thoracic radiotherapy for lung cancer. Eur J Cancer. 2001;37(1):54-63.

20. Yamada M, Kudoh S, Hirata K, Nakajima T, Yoshikawa J. Risk factors of pneumonitis following chemoradiotherapy for lung cancer. Eur J Cancer. 1998;34(1):71-5.

21. Jiang J, Liang X, Zhou X, Huang L, Huang R, Chu Z, et al. A meta-analysis of randomized controlled trials comparing irinotecan/platinum with etoposide/platinum in patients with previously untreated extensivestage small cell lung cancer. J Thorac Oncol. 2010;5(6):867-73.

22. Tamura K, Takada M, Kawase I, Tada T, Kudoh S, Okishio K, et al. Enhancement of tumor radio-response by irinotecan in human lung tumor xenografts. Jpn J Cancer Res. 1997;88(2):218-23. 
23. Jeong HC, Lee SY, Lee SY, Kim JH, Shin C, Shim JJ, et al. Phase II study of irinotecan plus cisplatin with concurrent radiotherapy for the patients with limited-disease small-cell lung cancer. Lung Cancer. 2006;53(3):361-6.

24. Khozin S, Blumenthal GM, Pazdur R. Real-world data for clinical evidence generation in oncology. J Natl Cancer Inst. 2017;109(11):djx187.

25. Dovedi SJ, Cheadle EJ, Popple AL, Poon E, Morrow M, Stewart R, et al. Fractionated radiation therapy stimulates antitumor immunity mediated by both resident and infiltrating polyclonal T-cell populations when combined with PD-1 blockade. Clin Cancer Res. 2017;23(18):5514-26.

26. Goto K, Ohe Y, Shibata T, Seto T, Takahashi T, Nakagawa K, et al. Combined chemotherapy with cisplatin, etoposide, and irinotecan versus topotecan alone as second-line treatment for patients with sensitive relapsed small-cell lung cancer (JCOG0605): a multicentre, open-label, randomised phase 3 trial. Lancet Oncol. 2016;17(8):1147-57.

27. Korkmaz T, Seber S, Kefeli U, Sari E, Canhoroz M, Oven B, et al. Comparison of second-line treatment outcomes between sensitive and refractory small cell lung cancer patients: a retrospective analysis. Clin Transl Oncol. 2013;15(7):535-40.

28. Menendez JA, Lupu R. Fatty acid synthase and the lipogenic phenotype in cancer pathogenesis. Nat Rev Cancer. 2007;7(10):763-77.

29. Rundle A, Madsen A, Orjuela M, Mooney L, Tang D, Kim M, et al. The association between benzo[a]pyreneDNA adducts and body mass index, calorie intake and physical activity. Biomarkers. 2007;12(2):123-32.

30. Barbosa AD, Savage DB, Siniossoglou S. Lipid droplet-organelle interactions: emerging roles in lipid metabolism. Curr Opin Cell Biol. 2015;35:91-7.

\section{Tables}

Table 1. Demographic characteristics of 4,446 patients with limited-disease small-cell lung cancer who received definite concurrent chemoradiotherapy 


\begin{tabular}{|ll|}
\hline Variables & LD stage $(\mathrm{n}=4,446)$ \\
\hline Age, years & $64 \pm 8.28$ \\
\hline$<65$ & $2,187(49.2)$ \\
$\geq 65$ & $2,259(50.8)$ \\
\hline Sex (male/female) & $3,797(85.4) / 649(14.6)$ \\
\hline Comorbidities & \\
\hline HBP & $2,361(39.1)$ \\
\hline DM & $1,334(22.1)$ \\
\hline Hypercholesterolemia & $2,314(38.3)$ \\
\hline First-line therapy & \\
\hline Combination CRT & \\
\hline Etoposide/platinum & $4,187(94.2)$ \\
\hline Irinotecan/platinum & $259(5.8)$ \\
\hline Second-line therapy & \\
\hline Combination therapy & \\
\hline Etoposide/platinum & $151(8.7)$ \\
\hline Irinotecan/platinum & $774(44.5)$ \\
\hline Single-agent therapy & \\
\hline Etoposide & $240(13.8)$ \\
\hline Irinotecan & \\
\hline Belotecan & \\
\hline Topotecan & \\
\hline
\end{tabular}

Values are presented as mean \pm standard deviation or number (\%).

LD limited disease; $H B P$ hypertension; $D M$ diabetes mellitus; $C R T$ chemoradiotherapy.

Table 2. Risk factors for overall survival in 4,496 patients with limited-disease small-cell lung cancer 


\begin{tabular}{|lllll|}
\hline & Univariate & \multicolumn{3}{l|}{ Multivariate } \\
& HR $(95 \% \mathrm{Cl})$ & $P$-value & HR $(95 \% \mathrm{Cl})$ & $P$-value \\
\hline Age, years $(\geq 65$ vs. $<65)$ & $1.61(1.45-1.82)$ & $<0.0001$ & $1.64(1.45-1.85)$ & $<0.0001$ \\
\hline Sex (male vs. female) & $1.17(1-1.37)$ & 0.05 & $1.16(0.99-1.37)$ & 0.06 \\
\hline HBP (HBP vs. normal) & $1.09(0.98-1.22)$ & 0.12 & $1.08(0.96-1.21)$ & 0.22 \\
\hline DM (DM vs. normal) & $1.05(0.93-1.19)$ & 0.41 & $1.06(0.93-1.2)$ & 0.41 \\
\hline Hypercholesterolemia (No vs. yes) & $1.15(1.03-1.28)$ & 0.01 & $1.23(1.10-1.39)$ & $<0.0001$ \\
\hline Definite CCRT (IP-CCRT vs. EP-CCRT) & $26.55(8.38-84.11)$ & $<0.0001$ & $19.47(6.13-61.77)$ & $<0.0001$ \\
\hline
\end{tabular}

$H R$, hazard ratio; $C l$, confidence interval; $H B P$, hypertension; $D M$, diabetes mellitus; $C C R T$, concurrent chemoradiotherapy; $I P$, irinotecan/platinum; $E P$, etoposide/platinum.

Table 3. Summary of previous studies on etoposide/cisplatin- or irinotecan/cisplatin-based concurrent chemoradiotherapy for limited-disease small-cell lung cancer 


\begin{tabular}{|c|c|c|c|c|c|c|c|c|}
\hline Author & Phase & $\begin{array}{l}\text { No. of } \\
\text { patients }\end{array}$ & Regimen & $\begin{array}{l}\text { Radiation } \\
\text { dose }\end{array}$ & $\begin{array}{l}\mathrm{RR} \\
(\%)\end{array}$ & $\begin{array}{l}\text { PFS (m), } \\
P \text {-value }\end{array}$ & $\begin{array}{l}\text { OS (m), } \\
P \text {-value }\end{array}$ & $\begin{array}{l}\text { Grade } 3 / 4 \\
\text { toxicity }(\%)\end{array}$ \\
\hline \multirow{4}{*}{$\begin{array}{l}\text { Faivre- } \\
\text { Finn [4] } \\
(2017)\end{array}$} & \multirow[t]{4}{*}{ III } & \multirow[t]{4}{*}{247} & \multirow{4}{*}{$\begin{array}{l}\text { EP-CCRT } \\
\text { BID vs. } \\
\text { QD }\end{array}$} & \multirow{4}{*}{$\begin{array}{l}45 \text { Gy vs. } \\
66 \text { Gy }\end{array}$} & & \multirow{2}{*}{$\begin{array}{l}15.4 \text { vs. } \\
13.4 ; \\
H R=1.12\end{array}$} & \multirow{3}{*}{$\begin{array}{l}30 \text { vs. } \\
25 \\
H R=1.18 \\
p=0 \cdot 14\end{array}$} & \\
\hline & & & & & & & & \\
\hline & & & & & & \multirow[t]{2}{*}{$p=0.26$} & & \\
\hline & & & & & & & $\begin{array}{l}\text { SR (56\% } \\
\text { vs. } 51 \%)\end{array}$ & $\begin{array}{l}\text { Radiation } \\
\text { pneumonitis ( } 3 \% \\
\text { vs. } 2 \%)\end{array}$ \\
\hline \multirow[t]{3}{*}{$\begin{array}{l}\text { Kubota } \\
{[12]} \\
(2014)\end{array}$} & \multirow[t]{3}{*}{ III } & \multirow[t]{3}{*}{281} & \multirow{3}{*}{$\begin{array}{l}\text { EP-CCRT } \\
\text { BID } \\
\text { followed } \\
\text { by IP vs. } \\
\text { EP }\end{array}$} & \multirow[t]{3}{*}{$45 \mathrm{~Gy}$} & & \multirow{3}{*}{$\begin{array}{l}12 \mathrm{vs} . \\
13.2 ; \mathrm{HR} \\
1.10 \\
p=0.74\end{array}$} & $\begin{array}{l}33.6 \text { vs. } \\
38.4 ; \\
H R=1 \cdot 09\end{array}$ & $\begin{array}{l}\text { Neutropenia } \\
\text { (95\% vs. } 78 \%)\end{array}$ \\
\hline & & & & & & & $\mathrm{p}=0 \cdot / 0$ & $\begin{array}{l}\text { Anemia (35\% vs. } \\
50 \%)\end{array}$ \\
\hline & & & & & & & $\begin{array}{l}\text { b-year } \\
\text { SR } \\
(33.7 \% \\
\text { vs. } \\
35.8 \%)\end{array}$ & $\begin{array}{l}\text { Diarrhea ( } 2 \% \text { vs. } \\
1 \%)\end{array}$ \\
\hline \multirow{4}{*}{$\begin{array}{l}\text { Fukuda } \\
{[11]} \\
(2012)\end{array}$} & \multirow[t]{4}{*}{$\|$} & \multirow[t]{4}{*}{34} & \multirow[t]{4}{*}{ IP-CCRT } & \multirow[t]{4}{*}{50 Gy } & \multirow[t]{4}{*}{100} & \multirow{4}{*}{$\begin{array}{l}14.3 \\
1-, 5- \\
\text { year SR } \\
(56.9 \% \\
30.2 \%)\end{array}$} & 44.5 & Neutropenia $38 \%$ \\
\hline & & & & & & & \multirow{3}{*}{$\begin{array}{l}\text { 2- and 5- } \\
\text { year SR } \\
(66.7 \% \text {, } \\
46.1 \%)\end{array}$} & Pneumonitis $6 \%$ \\
\hline & & & & & & & & Diarrhea 3\% \\
\hline & & & & & & & & Esophagitis $0 \%$ \\
\hline \multirow{2}{*}{$\begin{array}{l}\text { Naidu } \\
{[10]} \\
(2014)\end{array}$} & \multirow[t]{2}{*}{$\|$} & \multirow[t]{2}{*}{36} & \multirow{2}{*}{$\begin{array}{l}\text { IP-CCRT } \\
\text { BID }\end{array}$} & \multirow[t]{2}{*}{ 45-54 Gy } & \multirow[t]{2}{*}{67} & & 19 & $\begin{array}{l}\text { Symptomatic } \\
\text { pneumonitis } 0 \%\end{array}$ \\
\hline & & & & & & & $\begin{array}{l}\text { year SR } \\
(60 \% \text {, } \\
44 \% \text {, } \\
30 \%)\end{array}$ & $\begin{array}{l}\text { Symptomatic } \\
\text { esophagitis } 13 \%\end{array}$ \\
\hline \multirow{4}{*}{$\begin{array}{l}\text { Saito } \\
{[14]} \\
(2006)\end{array}$} & \multirow[t]{4}{*}{$\|$} & \multirow[t]{4}{*}{51} & \multirow{4}{*}{$\begin{array}{l}\text { EP-CCRT } \\
\text { BID } \\
\text { followed } \\
\text { by IP }\end{array}$} & $45 \mathrm{~Gy}$ & 88 & 11.8 & 23 & Neutropenia $88 \%$ \\
\hline & & & & & & & 2- and 3- & Infection 33\% \\
\hline & & & & & & & $\begin{array}{l}(49 \% \\
29.7 \%)\end{array}$ & $\begin{array}{l}\text { Electrolyte } \\
\text { imbalance 20\% }\end{array}$ \\
\hline & & & & & & & & Diarrhea $14 \%$ \\
\hline $\begin{array}{l}\text { Jeong } \\
\text { [2?] }\end{array}$ & $\|$ & 20 & IP-CCRT & $50.4 \mathrm{~Gy}$ & 85 & 12 & 20 & Neutropenia $60 \%$ \\
\hline (2006) & & & & & & $\begin{array}{l}\text { 1-year } \\
\text { SR } 36 \%\end{array}$ & $\begin{array}{l}\text { 1- and 2- } \\
\text { year SR } \\
(85 \% \text {, }\end{array}$ & $\begin{array}{l}\text { Anemia (20\%) } \\
\text { Nausea/vomiting } \\
(55 \%)\end{array}$ \\
\hline & & & & & & & & Diarrhea (35\%) \\
\hline $\begin{array}{l}\text { Hong } \\
{[13]}\end{array}$ & II & 19 & $\begin{array}{l}\text { IP-CCRT } \\
\text { OD }\end{array}$ & 54 Gy & 89.5 & 7.6 & 12.4; & $\begin{array}{l}\text { Radiation- } \\
\text { induced }\end{array}$ \\
\hline (2011) & & & & & & & $\begin{array}{l}\text { 2-year } \\
\text { SR } \\
(75.0 \%)\end{array}$ & $\begin{array}{l}\text { pneumonitis } 53 \% \\
\text { Neutropenia } 32 \%\end{array}$ \\
\hline
\end{tabular}




\begin{tabular}{|c|c|c|c|c|c|c|c|c|}
\hline $\begin{array}{l}\text { Sohn } \\
\text { [8] } \\
(2007)\end{array}$ & II & 33 & $\begin{array}{l}\text { IP-CCRT } \\
\text { BID }\end{array}$ & 45-54 Gy & 87.9 & $\begin{array}{l}14.4 \\
2-y e a r \\
\text { SR } \\
26.8 \%\end{array}$ & $\begin{array}{l}26.1 ; \\
\text { 2-year } \\
\text { SR } \\
(54.9 \%)\end{array}$ & $\begin{array}{l}\text { Neutropenia } \\
81.8 \% \\
\text { Diarrhea } 21.2 \% \\
\text { Radiation } \\
\text { pneumonitis } \\
9.1 \%\end{array}$ \\
\hline $\begin{array}{l}\text { Han } \\
{[15]} \\
(2005)\end{array}$ & II & 33 & $\begin{array}{l}\text { IP } \\
\text { followed } \\
\text { by EP- } \\
\text { CCRT } \\
\text { BID }\end{array}$ & $45 \mathrm{~Gy}$ & 97 & $\begin{array}{l}12.9 \\
2-y \text { ear } \\
\text { SR } \\
36.1 \% \text {, }\end{array}$ & $\begin{array}{l}25 ; \\
\text { 1- and 2- } \\
\text { year SR } \\
(85.7 \% \text {, } \\
53.9 \%)\end{array}$ & $\begin{array}{l}\text { Neutropenia } \\
(68 \%+100 \%)^{\mathrm{a}} \text {, } \\
\text { Febrile } \\
\text { neutropenia }(20 \% \\
+60 \%)^{\mathrm{b}}\end{array}$ \\
\hline \multicolumn{9}{|c|}{ 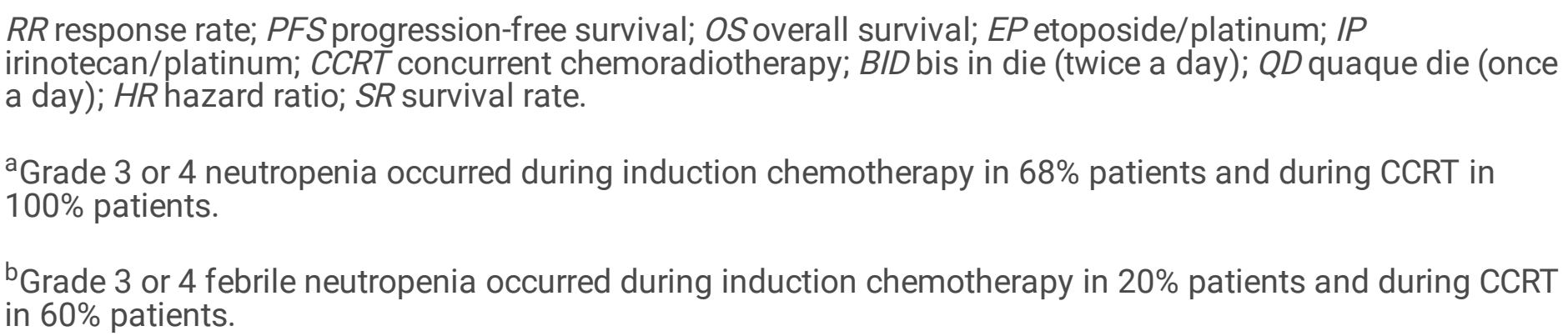 } \\
\hline
\end{tabular}

\section{Figures}
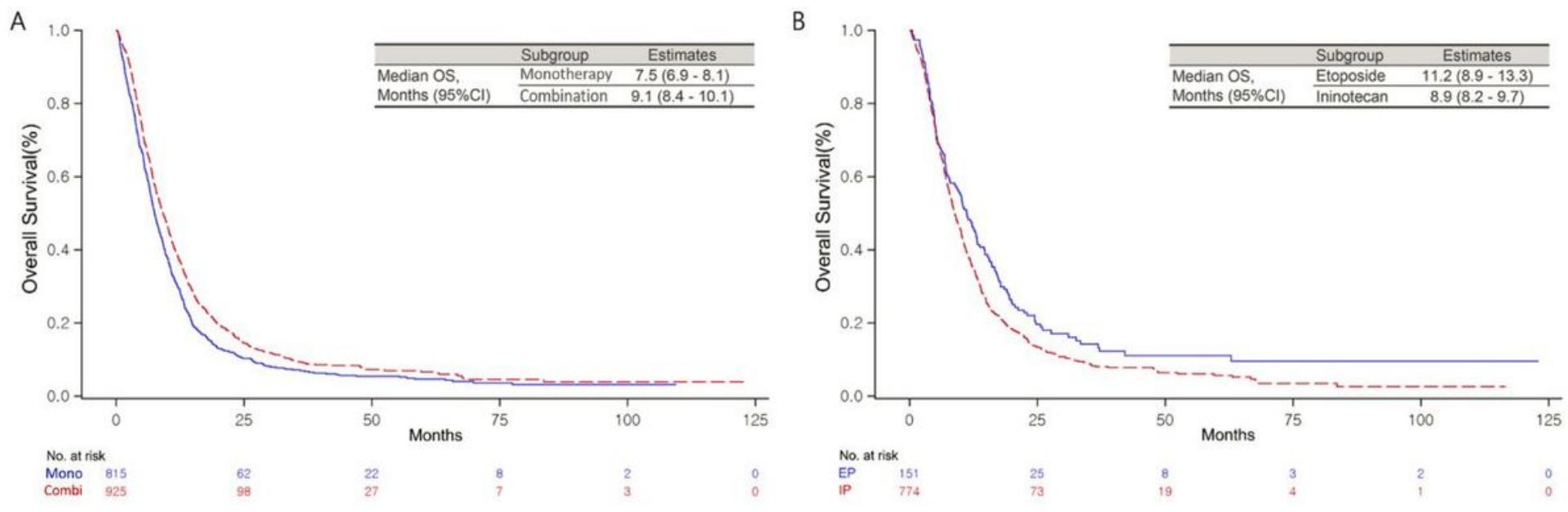

\section{Figure 1}

Data mining process for identification of patients with LD-SCLC. SCLC, small-cell lung cancer; CCRT, concurrent chemoradiotherapy; LD, limited-disease; ED, extensive-disease 


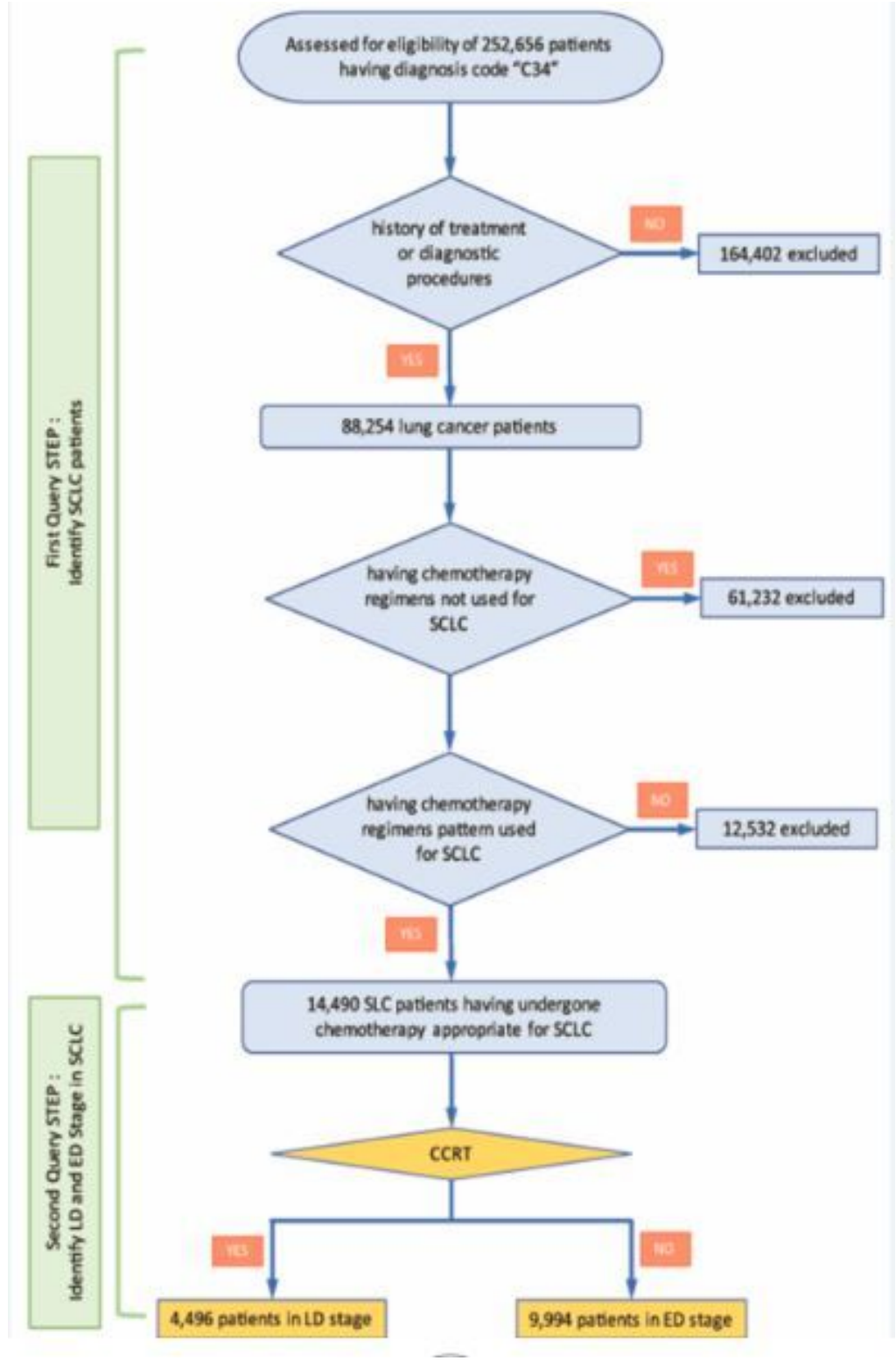

\section{Figure 2}

Kaplan-Meier curves for progression-free survival (PFS) (A) and overall survival (OS) (B) in patients who received an etoposide/platinum (EP)- or irinotecan/platinum (IP)-based concurrent chemoradiotherapy regimen as definite treatment for limited-disease small-cell lung cancer. $\mathrm{Cl}$, confidence interval 

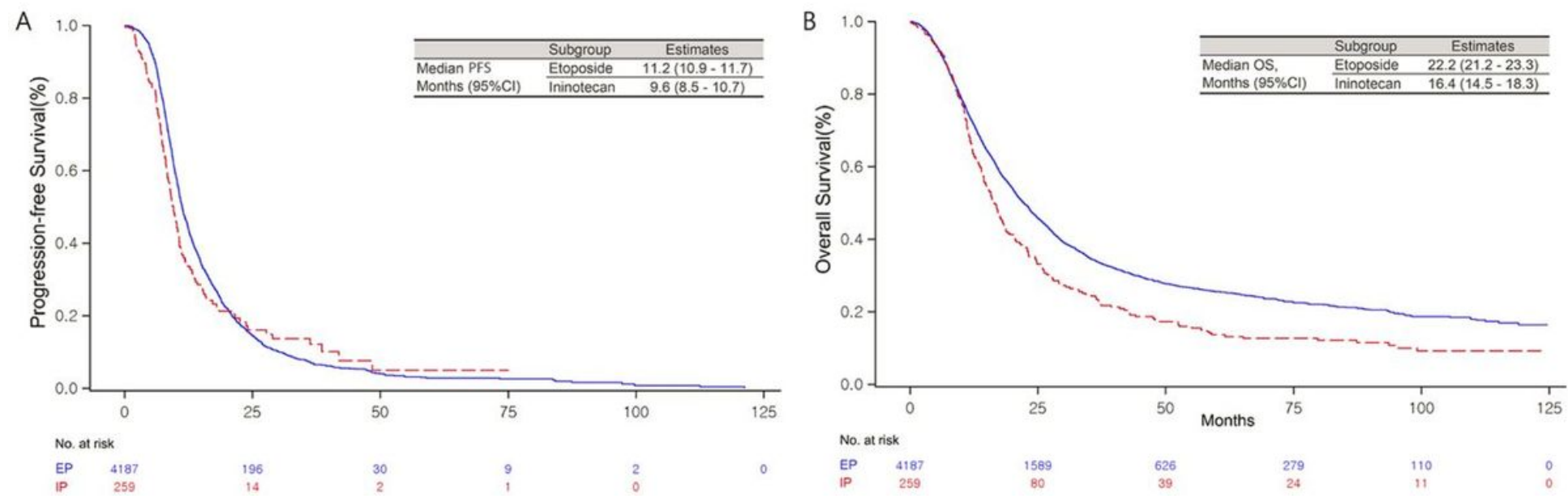

Figure 3

(A) Kaplan-Meier curves for overall survival (OS) in patients with limited-disease (LD) small-cell lung cancer (SCLC) who received combination chemotherapy (combi) or monotherapy (mono) as second-line treatment. (B) Kaplan-Meier curve for OS in patients with LD-SCLC who received the irinotecan/platinum (IP) or etoposide/platinum (EP) combination as second-line treatment. $\mathrm{Cl}$, confidence interval

\section{Supplementary Files}

This is a list of supplementary files associated with this preprint. Click to download.

- S3Fig.tif

- S2Fig.tif

- S1Fig.tif 